\title{
Antiangiogenic cancer therapy: why do mouse and human patients respond in a different way to the same drug?
}

\author{
YIHAI CAO* \\ Department of Microbiology, Tumor and Cell Biology, Karolinska Institute, Stockholm, Sweden
}

\begin{abstract}
The tumor vasculature is an increasingly attractive target for development of anticancer drugs. The fundamental principle for antiangiogenic cancer therapy is based on the inhibitory effect of chemical compounds, proteins or nucleotides on tumor angiogenesis. Indeed, in almost all preclinical tumor models, antiangiogenic monotherapy with different agents shows potent effects on suppression of tumor growth. However, antiangiogenic monotherapy has barely produced any clinical benefits in cancer patients. Although in combination with chemotherapy some antiangiogenic drugs demonstrate survival improvement in patients with certain types of cancers, the overall benefits by addition of antiangiogenic drugs (ADs) to chemotherapy remain modest. The disparity of $A D$ responses between preclinical models and clinical cancer patients has raised important issues, which include: 1) Are current animal tumor models appropriate for assessing the therapeutic efficacy of ADs for clinical development? 2) What are the key differences between mouse tumor models and human cancer patients? 3) Are anti-VEGF drugs off target in cancer patients? 4) What are alternative options for improvement of the clinical benefits of ADs? In this short review, I discuss these critical issues in relation to the clinical practice of ADs.
\end{abstract}

KEYWORDS: angiogenesis, cancer, targeted therapy, ocular disease, cardiovascular disease

\section{Introduction}

More than 40 years ago when Dr. Judah Folkman operated animal and human tumors, he noticed that tumor tissues are enriched in blood, which is supplied by tumor vessels (Folkman et al., 1971). Folkman, in a theoretical paper, proposed that all solid tumor growth is dependent on angiogenesis and suppression of tumor angiogenesis might offer a new option of cancer therapy (Folkman, 1971). To approve his hypothesis, Folkman's laboratory isolated blood vessel endothelial cells, purified the first angiogenic factor from tumors, developed ex-vivo and in vivo angiogenesis assays, isolated the first specific endogenous angiogenesis inhibitor and approved the antiangiogenic principle as a valid approach for cancer therapy in mice (Folkman et al., 1979; Langer et al., 1976; Shing et al., 1984). All these landmark studies have paved today's avenue for development of ADs by pharmaceutical companies and practice of antiangiogenic therapy in human cancer patients.

Among all known angiogenic pathways in tumors, the vascular endothelial growth factor (VEGF) signaling axis has become a central target for anticancer drug development (Cao, 2010, Hurwitz et al., 2004; Kerbel, 2008; Torino et al., 2009). Virtually all currently available ADs in the clinic contains anti-VEGF components, which include a VEGF neutralizing antibody, bevacizumab, and tyrosine kinase inhibitors targeting VEGF receptors such as sunitinib and sorafenib (Cao et al., 2007; Cao et al., 2009). Both genetic and epigenetic factors in the malignant tissue contribute to high expression levels of VEGF, which can be further elevated by hypoxia during tumor growth. Thus, VEGF is involved in the initial phase of tumor growth and later development and progression of the malignant disease. Constant high levels of VEGF in most tumors suggest anti-VEGF drugs should be persistently delivered to cancer patients (Cao et al., 2010).

In preclinical tumor models, most antiangiogenic agents delivered as monotherapy have demonstrated potent anticancer effects in a variety of tumor types (Kim et al., 1993; Millauer et al., 1994). Consistent with tumor suppression, tumor neovascularization is usually markedly reduced after treatment with these agents. Thus, the antiangiogenic principle for cancer therapy in mouse tumor models has validated Folkman's original hypothesis. However,

Abbreviations used in this paper: AD, antiangiogenic drug; Ang, angiopoietin; FGF-2, fibroblast growth factor-2; HGF, hepatocyte growth factor; IGF, insulin-like growth factor; TKRs, tyrosine kinase receptors; VEGF, vascular endothelial growth factor; VEGFR, VEGF receptor

\footnotetext{
*Address correspondence to: Yihai Cao. Department of Microbiology, Tumor and Cell Biology, Karolinska Institutet, 17177 Stockholm, Sweden. Fax: (+46)-8-33-1399. e-mail: yihai.cao@ki.se
} 
antiangiogenic monotherapy with most available drugs has not demonstrated clinical benefits in cancer patients (Cao, 2009; Hurwitz et al., 2004). Despite significant improvement of clinical outcome in combination with chemotherapy, survival benefits of ADs in combination settings remain modest in most cancer types (Kerbel, 2008). Although the common experience for general drug development shows a large gap between mouse and human responses, the antiangiogenic property of ADs should be the same for mouse and human tumor. Why do human cancer patients respond in a different way to the same drug? This review article attempts to discuss this important issue in relation to clinical practice of ADs.

\section{Antiangiogenic principles}

There are currently two classes of antiangiogenic agents that inhibit tumor angiogenesis: 1) Angiogenic pathway blockades and 2) Endogenous angiogenesis inhibitors (Folkman, 2007). Tumors produce a variety of angiogenic factors or cytokines to stimulate angiogenesis, which is essential for tumor growth and metastasis (Cao et al., 2007) (Fig. 1). These tumor-derived angiogenic factors include VEGF, fibroblast growth factor-2 (FGF-2), platelet-derived growth factor (PDGFs), angiopoietins (Angs), hepatocyte growth factor (HGF), and insulin-like growth factors (IGFs). The angiogenic signals triggered by these angiogenic factors are mediated by their specific tyrosine kinase receptors (TKRs) expressed in endothelial cells (Bjorndahl et al., 2005; Eriksson et al., 2002; Nissen et al., 2007; Xue et al., 2008). Giving the known information about signaling mechanisms, development of specific antagonists such as neutralizing antibodies, soluble receptors and intracellular tyrosine kinase inhibitors for therapeutic implications is a relatively straightforward approach (Cao, 2008; Dowlati, 2010; Force et al., 2007; Hurwitz et al., 2004; Kim et al., 1993; Millauer et al., 1994). Indeed, in preclinical models angiogenic factor antagonists such as bevacizumab show potent anticancer effects by neutralizing angiogenic signals in tumors (Kim et al., 1993). Because the molecular mechanisms of blocking angiogenic signaling pathways are obvious and well characterized, drug development based on these principles remains attractive for pharmaceutical companies.

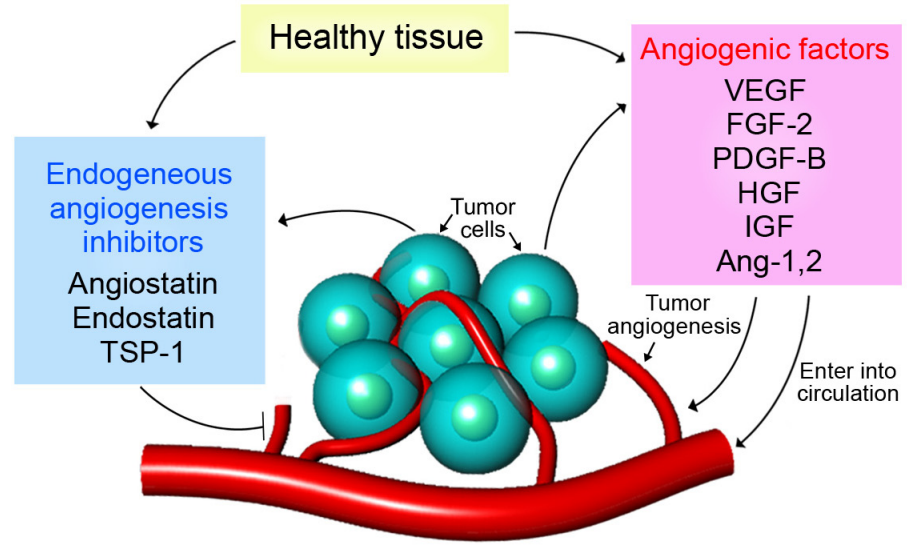

Fig. 1. Production of multiple angiogenic factors and inhibtors by both tumor cells and healthy tissues. These angiogenic factors in the tumor environment stimulate local angiogenesis and they could also enter into the circulation to induce destructive effects on healthy tissues and organs of the host.
Indeed, almost all currently available antiangiogenic drugs in the clinic are developed by antagonizing angiogenic pathways in tumors.

In contrast to angiogenic blockades, the molecular mechanisms of endogenous angiogenesis inhibitors such as angiostatin, endostatin and thrombospondin-1 remain enigmatic (Cao, 1998, 2001). Endogenous angiogenesis inhibitors have been reported to display broad-spectrum of inhibitory activities, which directly act on endothelial cells by blocking common pathways of various angiogenic factor-triggered angiogenesis (Fig. 1). However, they generally lack defined signaling pathways for endothelial inhibition. For example, specific endothelial cell receptors for angiostatin and endostatin and their signaling events remain unclear despite the early discovery of these inhibitors (O'Reilly et al., 1997; O'Reilly et al., 1994). This is probably one of the main reasons why pharmaceutical companies remain reluctant in further developing these inhibitors toward clinical use. Endogenous angiogenesis inhibitors displaying a broad spectrum of inhibitory activity would in principle more effective for therapy. The only clinically approved drug based on endogenous angiogenesis inhibitor is endostatin, which is only available in China for the treatment of lung cancer (Yang et al., 2006; Han et al., 2011).

\section{Differences between preclinical tumor models and human patients in relation to antiangiogenic therapy}

The most commonly used preclinical models for assessment of antiangiogenic and antitumor activities are xenograft tumor models in mice that carry implanted mouse or human tumors (Table 1). Typically, a large number of tumor cells $\left(1 \times 10^{5-6}\right)$ are subcutaneously implanted into each of mice and tumors grow to a size of 1.0 $\mathrm{cm}^{3}$ within a few weeks. Although this is a commonly used animal tumor model for studying antiangiogenic and antitumor effects of different molecules, the relevance of this xenograft model to clinical setting is far from reality. First, the subcutaneous implantation site does not usually represent physiologically orthotropic sites where human tumors arise. How many types of cancers do humans develop subcutaneously? In fact, the subcutaneous region is a rare site for development of human cancers. The tissue site is probably one of the important issues related to drug responses because angiogenic vessels in various tissues may express different receptors that are activated by specific ligands. Further, selective expression of different subsets of the same ligand receptors exists in different tissues. VEGFR1 and VEGFR2, for example, are differentially expressed in the retinal vasculature and blood vessels in other tissues (Cao et al., 2010; Saint-Geniez et al., 2008). Differential expression of angiogenic factor receptors in various tissues and organs may lead to distinctive AD responses.

Another key difference between human cancers and mouse tumor models is the speed of cancer development (Table 1). In human patients, spontaneous development of a clinical detectable cancer may take years whereas development of a similar size of a mouse tumor may only take weeks (O'Reilly et al., 1994). The differential growth rates between human and mouse tumors may create completely different environments, leading to dissimilar angiogenic profiles and drug responses. Typically, in a fast-growing mouse tumor, the growth of angiogenic vessels occurs behind the malignant tissue expansion, leading to a hypoxia environment. Tissue hypoxia is known to switch on hypoxia-inducible gene transcription of certain angiogenic factors such as VEGF and 
thus alter angiogenic profiles (Makino et al., 2001). In relatively slow-growing human tumors however, tissue hypoxia-induced angigiogenic profiles are less enunciated as mouse tumors. The difference of angiogenic profiles between human and mouse tumors in relation to the tumor growth rate may determine variation of drug responses.

In humans, cancer is usually considered as a common disease in the older population whereas in mouse tumor models relatively young animals are used for experimentation (Table 1). It is known that angiogenesis occurs at different rates in various aged populations (Rivard et al., 1999). For example, impaired angiogenesis in respond to tissue ischemia has been reported in aged rabbits (Rivard et al., 1999). Young human or animal subjects are susceptible to angiogenic stimuli by triggering relatively robust angiogenic responses under physiological and pathological settings. In contrast, old human or animal subjects often show delayed or impaired angiogenic responses under the same conditions. In general, it is speculated that high angiogenic profiles in tumors would be more prone to angiogenesis inhibition because the newly formed vasculature is dependent angiogenic stimuli.

In addition to the variation between human and mouse tumors, the genetic backgrounds in human patients and experimental mice are completely different (Table 1). In experimental mouse models, genetically identical inbred syngeneic strains are often used for tumor studies. Conversely, human tumors arise from genetically divergent populations that may show diverse responds to the same drug. Recent clinical experiences with ADs demonstrate that the polymorphism of certain angiogenesis-genes in cancer patients significantly confers the difference of AD responses in the patients with the same type of cancer. For example, patients with different VEGF or VEGFR polymorphisms show polarized survival responses to anti-VEGF drugs (Cao, 2010; Schneider et al., 2008). Similarly, phase III clinical trials demonstrate that differential responses to the same drug such as gefitinib exists among different races of human patients (Branca, 2005; Duster, 2007; Takeda et al., 2010). The genetic variation of individual human cancer patients cannot be appropriately recapitulated using experimental mouse models.

In mouse xenograft tumor models, treatments with antiangiogenic agents usually begin shortly after implantation of tumor cells (Table 1). However, antiangiogenic therapy for human cancer patients is only initiated at the advanced stage of an established malignant disease. Strictly speaking, current regimens for mouse cancer therapy by ADs is aimed for prevention of tumor growth but not specifically designed for the treatment of established tumors. One argument in opposition to the treatment of established mouse tumors is that antiangiogenic agents are supposed to inhibit tumor

\section{TABLE 1}

\section{DIFFERENCES BETWEEN HUMAN CANCER AND MOUSE TUMOR MODELS}

\begin{tabular}{lll} 
Features & Human patients & Experimental mouse patients \\
\hline Assessment & Survivals & Tumor size \\
Tumor site & Intrinsic & Often artificial \\
Tumor growth rate & Slow (often years) & Fast (often weeks) \\
Age & Usually old population & Young age \\
Genetic background & Heterogeneous & Homogeneous \\
Treatment & Treatment begins usually at the & Usually begins at the early stage of \\
& advanced stage of cancer & tumor development \\
\hline
\end{tabular}

growth rather than shrinkage of the tumor mass. Perhaps the critical and fundamental criteria for assessment of drug effects between preclinical models and clinical patients are different (see below). In mouse tumor models, we are usually studying the drug effect on tumor size, whereas in human patients survival improvements by ADs are often the endpoints of clinical outcomes.

Therapeutic efficacy of antiangiogenic agents is often assessed as monotherapy in mice whereas the same agents are delivered to cancer patients as combinatorial therapy with chemotoxic drugs (Table 1). The fact that antiangiogenic monotherapy often lacks clinical benefits undermines the relevance of mouse tumor models to human cancer patients. Despite this known fact, therapeutic assessments of antiangiogenic agents by monotherapy continue in mouse tumor models. Would combination therapy be more appropriate for preclinical evaluation of antiangiogenic agents? In mouse tumor models, delivery of chemotherapeutic drugs alone at the conventional dose levels often produces overwhelming antitumor effects and addition of antiangiogenic agents as an extra component would be difficult to enhance the chemotherapeutic effect.

To recapitulate clinical situation, spontaneous mouse tumor models have been used as an alternative option for preclinical assessment of antiangiogenic agents. In contrast to xenograft tumor models, spontaneous mouse tumor models provide an opportunity to study kinetics of tumor angiogenesis during the tumor development (Kandel et al., 1991). Furthermore, antiangiogenic agents can be delivered to animals at different stages of tumor development, allowing assessment of therapeutic efficacy of drugs under non-invasive conditions (Parangi et al., 1996). Despite these advantages, spontaneous mouse tumor models also suffer severe drawbacks, which include: 1) introduction of an activated endogenous oncoprotein into a specific cell type; 2) deletion or inactivation of tumor suppressor genes; 3 ) overexpression of viral oncoproteins in mice; and 4) exposure of animals to carcinogenic chemicals. Although in these spontaneous tumor models the angiogenic switch could occur at the predicted time point, genetic manipulation of mice by germ-line overexpressing oncogenes often lead to alteration of angiogenic profiles, which are far from clinic relevance. For example, in the Rip-Tap pancreatic tumor transgenic model the simian virus $40 \mathrm{~T}$ antigen (SV40 large T) potently induces VEGF expression (Catalano et al., 2002). If anti-VEGF agents are evaluated in this mouse tumor model, drug response would expectedly to be rigorous. However, tumors in human patients do not often express SV40 large T antigen. Recently, it has been reported that treatment of k-ras oncogene-driven genetically modified mouse tumors with antiangiogenic agents recapitulates clinical responses seen in patients (Francia et al., 2010; Singh et al., 2010). It remains to be seen if such animal tumor models would predict clinical benefits.

\section{Off-tumor targets of antiangiogenic drugs}

Current antiangiogenic drugs are delivered to cancer patients by systemic administration, which may lead to a global impact on healthy vasculatures distributed in multiple tissues and organs (Cao, 2010). In fact, current clinically available ADs significantly regress tumor-free microvasculatures in several tissues and organs in mouse models (Kamba et al., 2006). In the conventional view of anticancer drugs, off-tumor targets would be associated with 
unwanted adverse effects of drugs. Interestingly, clinical benefits of ADs have been positively associated with systemic syndromes such as skin rashes and hypertension, which are resulted from the systemic effects of the drugs (Cao, 2010; Ravaud et al., 2009). Why would these systemic effects be positively correlated with beneficial outcomes of these drugs? In preclinical tumor models, it has been demonstrated that antiangiogenic agents at a low dosage without affecting the tumor vasculature normalize vasculatures in healthy tissues including those fenestrated vasculatures in endocrine organs such as bone marrow, liver and adrenal gland (Xue et al., 2008). Normalization of tumor VEGF-induced vascular tortuosity in non-tumor tissues significantly prolongs survivals of tumor-bearing mice by improving the cancer associated systemic syndrome. These findings suggest that off-tumor targets of antiangiogenic agents offer alternative mechanisms of clinical benefits of ADs. Unfortunately, clinical trials based on improvement of paraneoplastic syndrome and cancer cachexia by ADs have neither been designed nor reported. Improvement of the cancer-associated systemic syndrome by ADs in correlation with prolongation of patient survivals warrants future clinical validation.

\section{Options for optimization of clinical benefits of antiangiogenic drugs}

Current available ADs in combination with chemotherapy for the treatment of cancer patients have produced only modest beneficial effects (Cao et al., 2009). Optimization of antiangiogenic therapy is urgently needed in order to maximize therapeutic efficacy of these drugs. Obviously, defining novel therapeutic targets other than VEGF would be an important approach to increase clinical responses because a majority of cancer patients remain intrinsic resistance to anti-VEGF therapy. Given the fact that most tumors produce a broad spectrum of angiogenic factors to stimulate angiogenesis and to sustain the established vasculature, it is unsurprising that blockade of a single angiogenic pathway would be insufficient to suppress tumor growth and multitargeted "dirty drugs" would be more effective. In support of this view, antiangiogenic monotherapy with tyrosine kinase inhibitors such as sunitinib and sorafenib targeting multiple signaling pathways demonstrates survival benefits in the treatment of metastatic renal cell carcinoma (Escudier et al., 2007; Motzer et al., 2006). Inversely, delivery of mono-specific ADs such as bevacizumab has not been demonstrated to be beneficial in clinical settings (Hurwitz et al., 2004). Thus, development of new generation of drugs targeting diverse angiogenic pathways is expected to improve clinical benefits of ADs. In preclinical tumor models, it has been shown that a combination of antiangiogenic agents with different mechanistic principles yields a synergistic effect on tumor suppression (Dorrell et al., 2007; Lode et al., 1999). Translation of this preclinical finding to patient therapy would suggest an organizing principle of antiangiogenic cancer therapy should be considered in the future clinical practice.

Another important aspect of optimizing antiangiogenic therapy is to develop best possible drug delivery systems that enable kinetic personalized therapy (Cao et al., 2010). Unlike preclinical animal tumor models, the genetic background of clinical patients is diversified. In the same origin of cancer, divergent but completely different patterns of angiogenic profiles may exist among patients with the same cancer. If so, a generalized therapeutic regimen with the same AD as the key composition would be irrational for all patients. Thus, a personalized or individualized therapeutic approach should be considered. Even though an individual patient originally is sensitive to a specific AD based on his/her angiogenic profiles, the same patient may develop evasive resistance to the same drug owing to alteration of angiogenic profiles in tumors (Cao et al., 2009). In such a scenario, kinetically monitoring of changes of angiogenic profiles that predict clinical responses would be desirable. It has been recently suggested that smart microchips embedded with different antiangiogenic or chemostatic drugs may release any available drugs at any given time (Cao et al., 2010). If such smart drug-microchips are available in the future, they would expected to substantially improve the therapeutic efficacy of antiangiogenic therapy.

Other approaches of optimization of antiangiogenic therapy include: 1) Define reliable biomarkers for patient selection and monitoring therapeutic benefits as exhaustively discussed elsewhere; 2) Development of appropriate animal tumor models that recapitulate drugs responses in cancer patients. Recently it has been reported that genetically modified mouse tumor models produce similar drug responses seen in patients (Singh et al., $2010)$; 3) Understanding molecular mechanisms of intrinsic and evasive refractoriness to antiangiogenic drugs; 4) Design both preclinical and clinical studies by sequential delivery of ADs and chemotherapeutic drugs. Sequential delivery of ADs followed by chemotherapeutics has recently been shown in mice to produce superior beneficial effects (Zhang et al., 2011); 5) Explore metronomic therapy in combination antiangiogenic therapy;6) Optimizing dosages for ADs in combination of chemotherapeutic drugs and 7) Considering long-term non-stop antiangiogenic therapy by reducing the high cost of these current expensive drugs.

\section{Outlook}

Cancer is a complex disease that encompasses both genetic and epigenetic alternation of malignant cells and the tumor environment (Hanahan et al., 2000). In cancer patients, genetic diversity of human populations may generate completely different angiogenic profiles in tumors despite presence of the same type of cancer in different patients. The diversity of genetic backgrounds and angiogenic profiles implies an individualized therapeutic approach should be given to patients and generalized therapy with the same regimen may represent clinical failures. In fact, with an exception of bevacizumab almost every one of more than a dozen phase 3 trials designed for targeted drugs in combination with standard chemotherapy fails to show survival advantages in the front-line therapy for the treatment of lung cancer (Francia et al., 2010). Taken considerations of the vast diversity of human cancer patients, such disappointing clinical outcomes may not be totally unexpected. Although clinical experiences show that antiangiogenic therapy remains ineffective and produces only modest survival benefits in a minority of patients, this statistically significant and clinically positive outcome is somehow surprisingly encouraging and validates Folkman's original hypothesis that targeting blood vessels is probably a more universal approach for cancer therapy.

Unlike humans, genetically inbred experimental homogenous mice represent the same background and tumors are artificially manipulated to grow at the same or at least a similar pace. Unsurprisingly, these genetically identical animals would produce a similar response to the same drug. Indeed, antiangiogenic mono- 
therapy in mice regardless of xenograft or genetic tumor models shows the predicted power of tumor suppression. Thus, this type of animal model would not be appropriate for assesment therapeutic efficacy of ADs in cancer patients. Do we have better options to do preclinical evaluation? The simple answer is probably not yet.

As new mechanistic information on tumor angiogenesis and new targeted ADs are available, it is expected that an organizing principle of antiangiogenic therapy would be more effective by employing different classes of drugs to overcome resistance. Development of smart drug-embedded microchip systems is probably an attractive approach for making personalized antiangiogenic therapy into a reality.

\section{Acknowledgements}

Ithank Ms. Sharon Lim for the artistic work. Y.C's laboratory is supported through research grants from the Swedish Research Council, the Swedish Cancer Foundation, the Karolinska Institute Foundation, the Karolinska Institute distinguished professor award, the Torsten Soderberg's foundation, the financial support from Imclone, the European Union Integrated Project of Metoxia (Projectno. 222741) and the European Research Council (ERC) advanced grant ANGIOFAT (Project no 250021).

\section{References}

BJORNDAHL M, CAO R, NISSEN LJ, CLASPER S, JOHNSON LA, XUE Y, ZHOU $Z$, JACKSON D, HANSEN AJ,CAO Y (2005). Insulin-like growth factors 1 and 2 induce lymphangiogenesis in vivo. Proc Natl Acad Sci USA 102: 15593-15598.

BRANCA MA (2005). BiDil raises questions about race as a marker. Nat Rev Drug Discov 4: 615-616.

CAO R, XUE Y, HEDLUND EM, ZHONG Z, TRITSARIS K, TONDELLIB, LUCCHINIF, ZHUZ, DISSING S,CAOY (2010). VEGFR1-mediated pericyte ablation links VEGF and PIGF to cancer-associated retinopathy. Proc NatIAcad Sci USA 107: 856-861.

CAO Y (1998). Endogenous angiogenesis inhibitors: angiostatin, endostatin, and other proteolytic fragments. Prog Mol Subcell Biol 20: 161-176.

CAOY (2001). Endogenous angiogenesis inhibitors and their therapeutic implications. Int J Biochem Cell Biol 33: 357-369.

CAO Y (2008). Molecular mechanisms and therapeutic development of angiogenesis inhibitors. Adv Cancer Res 100: 113-131.

CAO Y (2009). Tumor angiogenesis and molecular targets for therapy. Front Biosci 14: 3962-3973.

CAO Y (2010). Off-tumor target-beneficial site for antiangiogenic cancer therapy? Nat Rev Clin Oncol 7: 604-608.

CAO Y,LANGER R (2010). Optimizing the delivery of cancer drugs that block angiogenesis. Sci Transl Med 2: 15ps3.

CAO Y,LIU Q (2007). Therapeutic targets of multiple angiogenic factors for the treatment of cancer and metastasis. Adv Cancer Res 97: 203-224.

CAO Y, ZHONG W,SUN Y (2009). Improvement of antiangiogenic cancer therapy by understanding the mechanisms of angiogenic factor interplay and drug resistance. Semin Cancer Biol 19: 338-343.

CAO Y, ZHONG W, SUN Y (2009). Improvement of antiangiogenic cancer therapy by understanding the mechanisms of angiogenic factor interplay and drug resistance. Semin Cancer Biol 19: 338-343.

CATALANO A, ROMANO M, MARTINOTTI S,PROCOPIO A (2002). Enhanced expression of vascular endothelial growth factor (VEGF) plays a critical role in the tumor progression potential induced by simian virus 40 large $T$ antigen. Oncogene 21: 2896-2900.

DORRELL MI, AGUILAR E, SCHEPPKE L, BARNETT FH,FRIEDLANDER M (2007). Combination angiostatic therapy completely inhibits ocular and tumor angiogenesis. Proc Natl Acad Sci USA 104: 967-972.

DOWLATI A (2010). Hunting and trapping the vascular endothelial growth factor. $J$ Clin Oncol 28: 185-187.

DUSTER T (2007). Medicalisation of race. Lancet 369: 702-704.

ERIKSSON A, CAO R, PAWLIUK R, BERG SM, TSANG M, ZHOU D, FLEET C,
TRITSARIS K, DISSING S, LEBOULCH P,CAOY (2002). Placenta growth factor-1 antagonizes VEGF-induced angiogenesis and tumor growth by the formation of functionally inactive PIGF-1/VEGF heterodimers. Cancer Cell 1: 99-108.

ESCUDIER B, EISEN T, STADLER WM, SZCZYLIK C, OUDARD S, SIEBELS M, NEGRIER S, CHEVREAU C, SOLSKA E, DESAI AA, ROLLAND F, DEMKOW T, HUTSON TE, GORE M, FREEMAN S, SCHWARTZ B, SHAN M, SIMANTOV R,BUKOWSKI RM (2007). Sorafenib in advanced clear-cell renal-cell carcinoma. N Engl J Med 356: 125-134.

FOLKMAN J (1971). Tumor angiogenesis: therapeutic implications. N Engl J Med 285: 1182-1186.

FOLKMAN J (2007). Angiogenesis: an organizing principle for drug discovery? Nat Rev Drug Discov 6: 273-286.

FOLKMAN J, HAUDENSCHILD CC,ZETTER BR (1979). Long-term culture of capillary endothelial cells. Proc Natl Acad Sci USA 76: 5217-5221.

FOLKMAN J, MERLER E, ABERNATHY C, WILLIAMS G (1971). Isolation of a tumor factor responsible for angiogenesis. J Exp Med 133: 275-288.

FORCE T, KRAUSE DS,VAN ETTEN RA (2007). Molecular mechanisms of cardiotoxicity of tyrosine kinase inhibition. Nat Rev Cancer 7: 332-344.

FRANCIA G,KERBEL RS (2010). Raising the bar for cancer therapy models. Nat Biotechnol 28: 561-562.

HAN B, XIU Q, WANG H, SHEN J, GU A, LUO Y, BAI C, GUO S, LIU W, ZHUANG Z, ZHANG Y, ZHAO Y, JIANG L, ZHOU J, JIN X (2011). A Multicenter, Randomized, Double-Blind, Placebo-Controlled Study to Evaluate the Efficacy of PaclitaxelCarboplatin Alone or with Endostar for Advanced Non-small Cell Lung Cancer. $J$ Thorac Oncol 6: 1104-1109.

HANAHAN D,WEINBERG RA (2000). The hallmarks of cancer. Cell 100: 57-70.

HURWITZ H, FEHRENBACHER L, NOVOTNY W, CARTWRIGHT T, HAINSWORTH J, HEIM W, BERLIN J, BARON A, GRIFFING S, HOLMGREN E, FERRARA N, FYFE G, ROGERS B, ROSS R,KABBINAVAR F (2004). Bevacizumab plus irinotecan, fluorouracil, and leucovorin for metastatic colorectal cancer. $N$ Engl $J$ Med 350: 2335-2342.

KAMBAT, TAM BY, HASHIZUME H, HASKELLA, SENNINOB, MANCUSO MR, NORBERG SM, O'BRIEN SM, DAVIS RB, GOWEN LC, ANDERSON KD, THURSTON G, JOHO S, SPRINGER ML, KUO CJ,MCDONALD DM (2006). VEGF-dependent plasticity of fenestrated capillaries in the normal adult microvasculature. $A m \mathrm{~J}$ Physiol Heart Circ Physiol 290: H560-H576.

KANDEL J, BOSSY-WETZEL E, RADVANYI F, KLAGSBRUN M, FOLKMAN J,HANAHAN D (1991). Neovascularization is associated with a switch to the export of bFGF in the multistep development of fibrosarcoma. Cell 66: 1095-104.

KERBEL RS (2008). Tumor angiogenesis. N Engl J Med 358: 2039-2049.

KIM KJ, LIB, WINER J, ARMANINI M, GILLETT N, PHILLIPS HS,FERRARAN (1993). Inhibition of vascular endothelial growth factor-induced angiogenesis suppresses tumour growth in vivo. Nature 362: 841-844.

LANGER R, BREM H, FALTERMAN K, KLEIN M,FOLKMAN J (1976). Isolations of a cartilage factor that inhibits tumor neovascularization. Science 193: 70-72.

LODE HN, MOEHLER T, XIANG R, JONCZYK A, GILLIES SD, CHERESH DA,REISFELD RA (1999). Synergy between an antiangiogenic integrin alphav antagonist and an antibody-cytokine fusion protein eradicates spontaneous tumor metastases. Proc Natl Acad Sci USA 96: 1591-1596.

MAKINO Y, CAO R, SVENSSON K, BERTILSSON G, ASMAN M, TANAKA H, CAO $Y, B E R K E N S T A M A, P O E L L I N G E R L$ (2001). Inhibitory PAS domain protein is a negative regulator of hypoxia-inducible gene expression. Nature 414: 550-554.

MILLAUERB, SHAWVERLK, PLATE KH, RISAU W, ULLRICHA (1994). Glioblastoma growth inhibited in vivo by a dominant-negative Flk-1 mutant. Nature 367:576-579.

MOTZERRJ, MICHAELSONMD, REDMANBG, HUDES GR, WILDING G, FIGLINRA, GINSBERG MS, KIM ST, BAUM CM, DEPRIMO SE, LI JZ, BELLO CL, THEUER CP, GEORGE DJ,RINI BI (2006). Activity of SU11248, a multitargeted inhibitor of vascular endothelial growth factor receptor and platelet-derived growth factor receptor, in patients with metastatic renal cell carcinoma. J Clin Oncol 24: 16-24.

NISSEN LJ, CAO R, HEDLUND EM, WANG Z, ZHAO X, WETTERSKOG D, FUNA K, BRAKENHIELM E,CAO Y (2007). Angiogenic factors FGF2 and PDGF-BB synergistically promote murine tumor neovascularization and metastasis. J Clin Invest 117: 2766-2777.

O'REILLY MS, BOEHM T, SHING Y, FUKAI N, VASIOS G, LANE WS, FLYNN E, BIRKHEAD JR, OLSEN BR,FOLKMAN J (1997). Endostatin: an endogenous inhibitor of angiogenesis and tumor growth. Cell 88: 277-285. 


\section{Y. Cao}

O'REILLY MS, HOLMGREN L, SHING Y, CHEN C, ROSENTHAL RA, MOSES M, LANE WS, CAO Y, SAGE EH,FOLKMAN J (1994). Angiostatin: a novel angiogenesis inhibitor that mediates the suppression of metastases by a Lewis lung carcinoma. Cell 79: 315-328.

PARANGI S, O'REILLY M, CHRISTOFORI G, HOLMGREN L, GROSFELD J, FOLKMAN J,HANAHAN D (1996). Antiangiogenic therapy of transgenic mice impairs de novo tumor growth. Proc Natl Acad Sci USA 93: 2002-2007.

RAVAUD A,SIRE M (2009). Arterial hypertension and clinical benefit of sunitinib, sorafenib and bevacizumab in first and second-line treatment of metastatic renal cell cancer. Ann Oncol 20: 966-967; author reply 967.

RIVARD A, FABRE JE, SILVER M, CHEN D, MUROHARAT, KEARNEY M, MAGNER M, ASAHARA T,ISNER JM (1999). Age-dependent impairment of angiogenesis. Circulation 99: 111-120.

SAINT-GENIEZ M, MAHARAJ AS, WALSHE TE, TUCKER BA, SEKIYAMA E, KURIHARA T, DARLAND DC, YOUNG MJ,D'AMORE PA (2008). Endogenous VEGF is required for visual function: evidence for a survival role on muller cells and photoreceptors. PLoS One 3: e3554.

SCHNEIDER BP, WANG M, RADOVICH M, SLEDGE GW, BADVE S, THOR A, FLOCKHARTDA, HANCOCK B, DAVIDSON N, GRALOWJ, DICKLER M, PEREZ EA, COBLEIGH M, SHENKIER T, EDGERTON S,MILLER KD (2008). Association of vascular endothelial growth factor and vascular endothelial growth factor receptor-2 genetic polymorphisms with outcome in a trial of paclitaxel compared with paclitaxel plus bevacizumab in advanced breast cancer: ECOG 2100. J Clin Oncol 26: 4672-4678.

SHING Y, FOLKMAN J, SULLIVAN R, BUTTERFIELD C, MURRAY J,KLAGSBRUN $M$ (1984). Heparin affinity: purification of a tumor-derived capillary endothelial cell growth factor. Science 223: 1296-1299.
SINGH M, LIMA A, MOLINA R, HAMILTON P, CLERMONT AC, DEVASTHALI V, THOMPSON JD, CHENG JH, BOU RESLAN H, HO CC, CAO TC, LEE CV, NANNINI MA, FUH G, CARANO RA, KOEPPEN H, YU RX, FORREST WF, PLOWMAN GD,JOHNSON L (2010). Assessing therapeutic responses in Kras mutant cancers using genetically engineered mouse models. Nat Biotechnol 28: 585-593.

TAKEDAK, HIDAT, SATOT, ANDO M, SETOT, SATOUCHI M, ICHINOSEY, KATAKAMI $\mathrm{N}$, YAMAMOTO N, KUDOH S, SASAKI J, MATSUI K, TAKAYAMA K, KASHII T, IWAMOTO Y, SAWA T, OKAMOTO I, KURATA T, NAKAGAWA K,FUKUOKA M (2010). Randomized phase III trial of platinum-doublet chemotherapy followed by gefitinib compared with continued platinum-doublet chemotherapy in Japanese patients with advanced non-small-cell lung cancer: results of a west Japan thoracic oncology group trial (WJTOG0203). J Clin Oncol 28: 753-760.

TORINO F, CORSELLO SM, LONGO R, BARNABEI A,GASPARINI G (2009). Hypothyroidism related to tyrosine kinase inhibitors: an emerging toxic effect of targeted therapy. Nat Rev Clin Oncol 6: 219-228.

XUE Y, RELIGA P, CAO R, HANSEN AJ, LUCCHINI F, JONES B, WU Y, ZHU Z, PYTOWSKI B, LIANG Y, ZHONG W, VEZZONI P, ROZELL B,CAO Y (2008). Anti-VEGF agents confer survival advantages to tumor-bearing mice by improving cancer-associated systemic syndrome. Proc NatlAcad SciUSA 105: 18513-18518.

YANG L, WANG JW, SUN Y, ZHU YZ, LIU XQ, LI WL, DI LJ, LI PW, WANG YL, SONG SP, YAO C, YOU LF (2006). [Randomized phase II trial on escalated doses of Rh-endostatin ( $\mathrm{YH}-16)$ for advanced non-small cell lung cancer]. Zhonghua Zhong Liu Za Zhi 28: 138-141.

ZHANG D, HEDLUND EM, LIM S, CHEN F, ZHANG Y, SUN B, CAO Y (2011). Antiangiogenic agents significantly improve survival in tumor-bearing mice by increasing tolerance to chemotherapy-induced toxicity. Proc Natl Acad Sci U S A 108: 4117-4122. 


\section{Further Related Reading, published previously in the Int. J. Dev. Biol.}

Insulin-like growth factor-2 regulates early neural and cardiovascular system development in zebrafish embryos Lori Hartnett, Catherine Glynn, Catherine M. Nolan, Maura Grealy and Lucy Byrnes Int. J. Dev. Biol. (2010) 54: 573-583

The seminal work of Werner Risau in the study of the development of the vascular system Domenico Ribatti

Int. J. Dev. Biol. (2010) 54: 567-572

Estrogen regulation of placental angiogenesis and fetal ovarian development during primate pregnancy Eugene D. Albrecht and Gerald J. Pepe Int. J. Dev. Biol. (2010) 54: 397-407

Uteroplacental vascular development and placental function: an update Lawrence P. Reynolds, Pawel P. Borowicz, Joel S. Caton, Kimberly A. Vonnahme, Justin S. Luther, David S. Buchanan, Shireen A. Hafez, Anna T. Grazul-Bilska and Dale A. Redmer

Int. J. Dev. Biol. (2010) 54: 355-365

Critical growth factors and signalling pathways controlling human trophoblast invasion Martin Knöfler

Int. J. Dev. Biol. (2010) 54: 269-280

Over-expression of thymosin beta4 promotes abnormal tooth development and stimulation of hair growth Hee-Jae Cha, Deborah Philp, Soo-Hyun Lee, Hye-Sung Moon, Hynda K. Kleinman and Takashi Nakamura Int. J. Dev. Biol. (2010) 54: 135-140

The contribution of Roberto Montesano to the study of interactions between epithelial sheets and the surrounding extracellular matrix

Domenico Ribatti

Int. J. Dev. Biol. (2010) 54: 1-6

A critical role for myoglobin in zebrafish development

Danielle H. Vlecken, Janwillem Testerink, Elisabeth B. Ott, Philippe A. Sakalis, Richard T. Jaspers and Christoph P. Bagowski Int. J. Dev. Biol. (2009) 53: 517-524

\section{Embryonic development of the proepicardium and coronary vessels}

Anna Ratajska, Elzbieta Czarnowska and Bogdan Ciszek

Int. J. Dev. Biol. (2008) 52: 229-236

Vasculogenesis and angiogenesis in the mouse embryo studied using quail/mouse chimeras Michel Pudliszewski and Luc Pardanaud Int. J. Dev. Biol. (2005) 49: 355-361

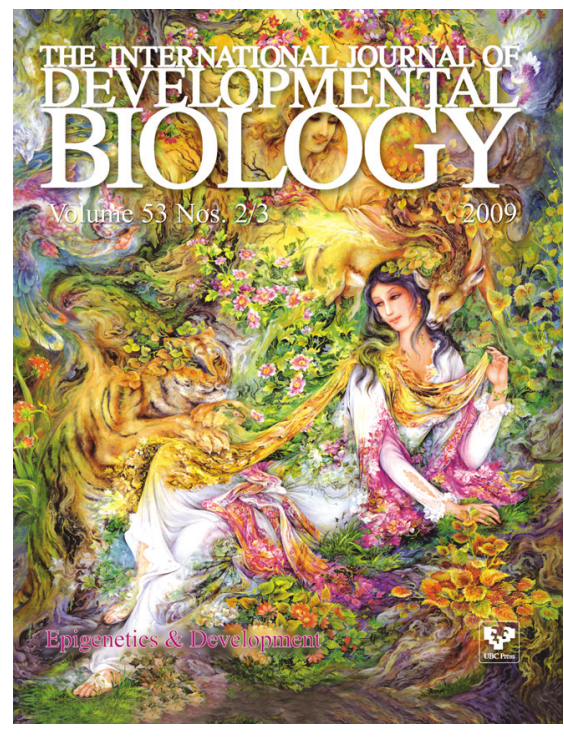
5 yr ISI Impact Factor $(2009)=3.253$

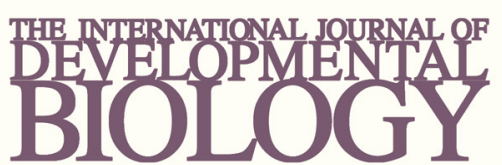

Volume 54 Nos. 6/7
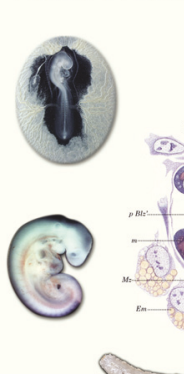

Developmental Hematopoiesis
Special Issue
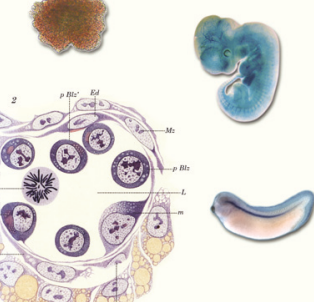

wack

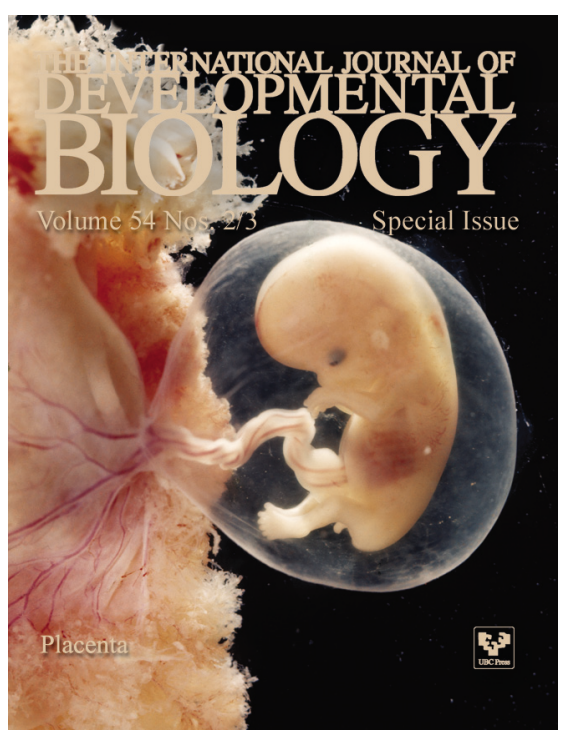

